\title{
Separation and determination of fluoride in plant samples
}

\author{
H.B. Li *, X.R. Xu \\ State Key Laboratory of Environmental Aquatic Chemistry, Research Center for Eco-Environmental Sciences, \\ Chinese Academy of Sciences, P.O. Box 2871, Beijing 100085, People's Republic of China
}

Received 2 February 1998; received in revised form 1 June 1998; accepted 8 June 1998

\begin{abstract}
A simple and rapid separation method is described for the determination of fluoride in plant samples. Fluoride is separated by distillation in the presence of $\mathrm{H}_{2} \mathrm{SO}_{4}$ and $\mathrm{H}_{2} \mathrm{O}_{2}$ in a dry air steam. The variables that influence the distillation quantitation were optimized. The fluorides separated were subsequently determined by a spectrophotometric method of the $\mathrm{La}(\mathrm{III})-\mathrm{F}^{-}$-alizarin complexone system. The precision of the procedure was significant, and the RSD was $3.7 \%$. The accuracy of the method was statistically satisfactory, and the recovery was from 95.9 to $104.4 \%$. (C) 1999 Elsevier Science B.V. All rights reserved.
\end{abstract}

Keywords: Fluoride; Separation; Distillation; Determination; Plant sample

\section{Introduction}

The effect of fluoride on human beings has a dual role as an essential trace element and at high levels as a toxic substance. Therefore, fluoride has received much attention with regard to medicine, pharmacy, public health and environmental protection. It is important and necessary to determine fluoride of plants because fluoride is known to affect various types of plants and, thus, both man and animals are susceptible to poisoning by fluoride-contaminated food or feedstuffs.

\footnotetext{
* Corresponding author. E-mail: xuxr@mail.rcees.ac.cn
}

Fluoride determination can sometimes be carried out in the presence of matrix compounds and by adding, if necessary, a complexing agent. Generally, however, fluoride must be separated to avoid interference. The separation methods for plant samples are mainly distillation after mineralization in an alkaline medium [1,2], and diffusion, either with or without ashing [3,4]. The distillation is time-consuming and the volume of the distilled fraction is too large. Diffusion allows the separation of a large number of samples at the same time. However, it also takes a long time when only a few samples need to be handled.

In this paper, a simple and rapid method to separate fluoride from plant samples is developed. 


\section{Experimental}

\subsection{Apparatus}

A 721 spectrophotometer (Shanghai No.3 Analytical Instrument Factory) was used.

\subsection{Reagents}

$\mathrm{NaF}, \mathrm{H}_{2} \mathrm{SO}_{4}, \mathrm{H}_{2} \mathrm{O}_{2}, \mathrm{NaOH}$ and $\mathrm{HCl}$ were all commercially available (made in China) and were used without any further purification except where it is stated. All reagents were puprapure or analytical pure grade. Deionized water was used throughout. Concentrated $\mathrm{H}_{2} \mathrm{SO}_{4}$ was heated till sulfur trioxide white smoke was produced in order to get rid of fluoride. The standard sodium fluoride solution was $1000 \mu \mathrm{g} \mathrm{ml}{ }^{-1}$. A stock solution of the fluoride ion $\left(1000 \mu \mathrm{g} \mathrm{ml}^{-1}\right)$ was prepared by dissolving $0.2210 \mathrm{~g}$ sodium fluoride, maintained under well-dried conditions, in $100 \mathrm{ml}$ water and stored in a polyethylene bottle. The working solution was prepared by suitable dilution of the stock solution with water.

\subsection{Procedure}

The plant samples were put into a round-bottom flask. The apparatus was installed as shown in Fig. 1. $\mathrm{NaOH}$ solution was added preliminarily into the gas-washing bottle in order to get rid of the fluoride in the air. $\mathrm{NaOH}$ solution was added in advance to the collector. Phenolphthalein was added as an indicator if determined by spectrophotometry. The operating process used the following steps: The tap to fill the separating funnel with water was turned on. Then the piston of the separating funnel was turned on to add water to the glass bottle so that the air was forced out. The air entered the round-bottom flask through the gas-washing bottle. Carrying with $\mathrm{HF}$ and $\mathrm{SiF}_{4}$, it arrived at the collector. $\mathrm{H}_{2} \mathrm{SO}_{4}$ was added by the sample-adding apparatus. Then $\mathrm{H}_{2} \mathrm{O}_{2}$ was dripped into the round-bottom flask by

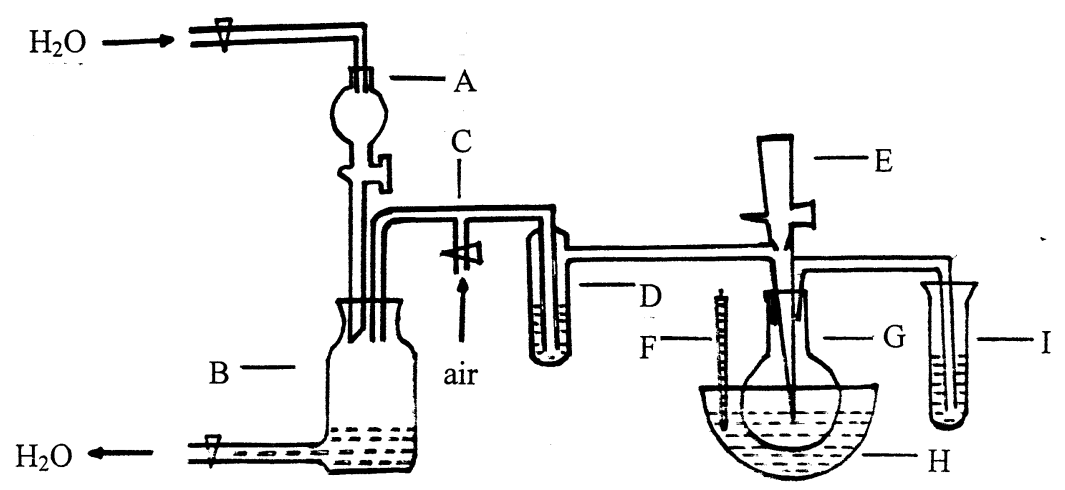

Fig. 1. Separating apparatus: (A) separating funnel; (B) glass bottle; (C) three-way pipe; (D) gas-washing bottle; (E) sample-adding apparatus; (F) thermometer; $(\mathrm{G})$ round-bottom flask; (H) oil bath; (I) collector.

Table 1

Results of collecting fractions of tea

\begin{tabular}{|c|c|c|c|c|c|}
\hline \multirow[t]{2}{*}{ Temperature $\left({ }^{\circ} \mathrm{C}\right)$} & \multicolumn{4}{|c|}{ Time (min) } & \multirow[t]{2}{*}{ Total value $\left(\mu \mathrm{g} \mathrm{g}^{-1}\right)$} \\
\hline & 10 & 20 & 30 & 40 & \\
\hline 150 & 108.6 & 17.5 & 7.0 & $\ldots^{\mathrm{a}}$ & 134.0 \\
\hline 160 & 143.3 & 10.8 & - & - & 154.2 \\
\hline 170 & 176.5 & - & - & - & 176.5 \\
\hline
\end{tabular}

a Nothing was detected. 
Table 2

The precision of the method for mulberry leaf samples

\begin{tabular}{|c|c|c|c|c|c|c|c|c|c|c|c|c|c|}
\hline Sample No. & 1 & 2 & 3 & 4 & 5 & 6 & 7 & 8 & 9 & 10 & $X$ & $\mathrm{SD}$ & $\operatorname{RSD}(\%)$ \\
\hline $\mathrm{F}$ found $\left(\mu \mathrm{g} \mathrm{g}^{-1}\right)$ & 31.2 & 28.5 & 30.5 & 32.5 & 29.8 & 30.1 & 30.9 & 29.5 & 32.0 & 31.5 & 30.7 & 1.1 & 3.7 \\
\hline
\end{tabular}

Table 3

The recovery of the method for mulberry leaf samples

\begin{tabular}{|c|c|c|c|c|c|c|c|c|c|c|}
\hline Sample No. & 1 & 2 & 3 & 4 & 5 & 6 & 7 & 8 & 9 & 10 \\
\hline Mass (mg) & 348.2 & 461.3 & 401.8 & 362.1 & 487.3 & 422.8 & 367.9 & 413.4 & 390.6 & 403.4 \\
\hline $\mathrm{F}$ found $(\mu \mathrm{g})$ & 12.1 & 12.5 & 11.3 & 11.9 & 12.7 & 12.9 & 11.8 & 11.4 & 12.6 & 12.4 \\
\hline $\mathrm{F}$ added $(\mu \mathrm{g})$ & 12.0 & 12.0 & 12.0 & 12.0 & 12.0 & 24.0 & 24.0 & 24.0 & 24.0 & 24.0 \\
\hline $\mathrm{F}$ found $(\mu \mathrm{g})$ & 23.6 & 24.3 & 23.8 & 24.0 & 24.6 & 36.8 & 36.0 & 35.2 & 36.9 & 36.1 \\
\hline Recovery $(\%)$ & 95.9 & 98.4 & 104.4 & 100.8 & 99.2 & 99.2 & 101.7 & 98.2 & 102.4 & 97.6 \\
\hline
\end{tabular}

the sample-adding apparatus. The temperature of the glycerin bath was controlled with an adjustable transformer. If the air was supplied by a pump and an electrothermal cap was used, the operation process was simpler and easier.

Dried plant samples $(0.3-0.5 \mathrm{~g})$ (such as tea leaves, tobacco leaves, and mulberry leaves) were placed into the distillation bottle and linked to every part as shown in Fig. 1. Concentrated $\mathrm{H}_{2} \mathrm{SO}_{4}$ $(5 \mathrm{ml})$ was added at $110^{\circ} \mathrm{C}$ and $8 \mathrm{ml} 30 \% \mathrm{H}_{2} \mathrm{O}_{2}$ solution was added dropwise. The samples were distilled at $175-180^{\circ} \mathrm{C}$ for $10 \mathrm{~min}$. Then the distillation was continued for 5 min after $2 \mathrm{ml} \mathrm{30 \%} \mathrm{H}_{2} \mathrm{O}_{2}$ was added dropwise. The flow rate of the carrier gas was $0.41 \mathrm{~min}^{-1}$. The Time to add concentrated $\mathrm{H}_{2} \mathrm{SO}_{4}$ and $\mathrm{H}_{2} \mathrm{O}_{2}$ was 10 min followed by distillation at $175-180^{\circ} \mathrm{C}$ for $15 \mathrm{~min}$. Therefore, it took about 25-30 min to process a sample.

The effect of the separation was studied by a spectrophotometric method of the $\mathrm{La}(\mathrm{III})-\mathrm{F}^{-}-$ alizarin complexone system. The process was carried out according to Ref. [5].

\section{Results and discussion}

There were many factors affecting the separation. Here only the concentrations of $\mathrm{H}_{2} \mathrm{SO}_{4}$ and $\mathrm{H}_{2} \mathrm{O}_{2}$, the heating temperature and time were studied. Other factors, such as the flow rate of the carrier gas, $0.41 \mathrm{~min}^{-1}$, the volume of the round- bottom flask, $100 \mathrm{ml}$, the distance from the top of the tube to the bottom of the flask, $0.5 \mathrm{~cm}$, were kept constant.

\subsection{Effect of $\mathrm{H}_{2} \mathrm{SO}_{4}$ concentration}

Under the conditions of the addition of $10 \mathrm{ml}$ $30 \% \mathrm{H}_{2} \mathrm{O}_{2}$, and heating for $20 \mathrm{~min}$ at $180^{\circ} \mathrm{C}$, for $0.3-0.5 \mathrm{~g}$ dried tea samples, no effect was seen on the separation when the volume of concentrated $\mathrm{H}_{2} \mathrm{SO}_{4}$ was from 3 to $6 \mathrm{ml}$. However, when the volume of concentrated $\mathrm{H}_{2} \mathrm{SO}_{4}$ was less than $5 \mathrm{ml}$, white precipitation was produced in the digested solution. If the volume of concentrated $\mathrm{H}_{2} \mathrm{SO}_{4}$ was $5 \mathrm{ml}$ or more, then no white precipitation was produced and the digested solution was clear. The white precipitation may be $\mathrm{CaSO}_{4}$. When the volume of concentrated $\mathrm{H}_{2} \mathrm{SO}_{4}$ was more than $5 \mathrm{ml}$, the precipitation could be turned into soluble $\mathrm{Ca}\left(\mathrm{HSO}_{4}\right)_{2}$. Consequently, $5 \mathrm{ml}$ concentrated $\mathrm{H}_{2} \mathrm{SO}_{4}$ was chosen. It was noted that less acid fog was produced if the drop rate of $\mathrm{H}_{2} \mathrm{SO}_{4}$ to $\mathrm{H}_{2} \mathrm{O}_{2}$ was controlled properly.

\subsection{Effect of $\mathrm{H}_{2} \mathrm{O}_{2}$ concentration}

Under the conditions of the addition of $5 \mathrm{ml}$ concentrated $\mathrm{H}_{2} \mathrm{SO}_{4}$, and heating for $20 \mathrm{~min}$ at $180^{\circ} \mathrm{C}$, for $0.3-0.5 \mathrm{~g}$ dried tea samples, the effect of separation was almost constant when the volume of $30 \% \mathrm{H}_{2} \mathrm{O}_{2}$ was more than $8 \mathrm{ml}$. If the differences 


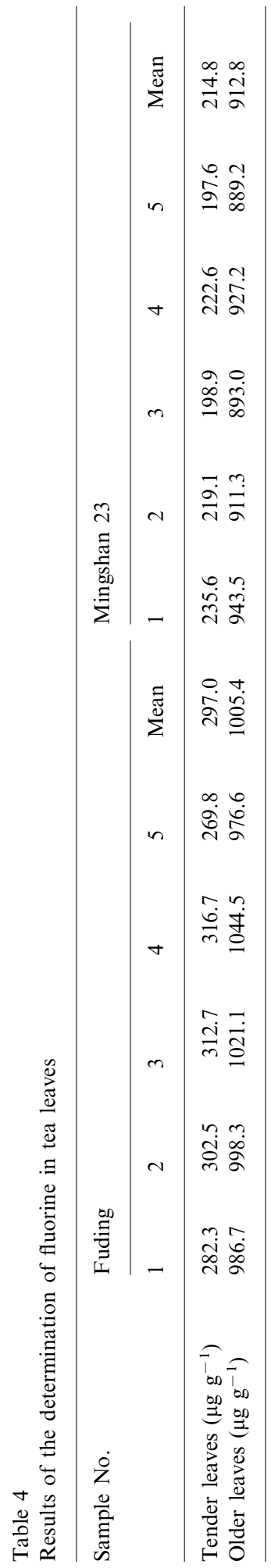


in plant samples were considered, the volume of $30 \% \mathrm{H}_{2} \mathrm{O}_{2}$ in later experiments should be $10 \mathrm{ml}$ to ensure complete digestion. Furthermore, surplus $\mathrm{H}_{2} \mathrm{O}_{2}$ decomposed to $\mathrm{H}_{2} \mathrm{O}$ and $\mathrm{O}_{2}$, which had no effect on the determination of fluoride. So $\mathrm{H}_{2} \mathrm{O}_{2}$ could be added in excess.

\subsection{Effect of temperature and time}

Under the conditions of the addition of $5 \mathrm{ml}$ concentrated $\mathrm{H}_{2} \mathrm{SO}_{4}$ and $10 \mathrm{ml} 30 \% \mathrm{H}_{2} \mathrm{O}_{2}$, for 0.3-0.5 g dried samples, the results for the collected fraction of tea are shown in Table 1. From the data in Table 1, it can be seen that the separation was complete when heated for $10 \mathrm{~min}$ at $170^{\circ} \mathrm{C}$ considering the difference between the parallel samples. Therefore, the heating temperature was controlled at $175-180^{\circ} \mathrm{C}$. Considering the diluting effect of collecting at different sections, the heating time should be $10-15 \mathrm{~min}$.

\subsection{Blank and absorption}

The blank value was found to be almost zero by doing five experiments. Additionally, the secondorder water absorption experiment was carried out using $95 \mathrm{~g} \mathrm{~F} \mathrm{~F}^{-}$(five times). That is, two gas-washing bottles were used in tandem and the second bottle absorbed the gas from the first bottle. There was no fluoride detected in the second bottle. Thus, it could be seen that the fluoride compounds can be absorbed completely by first-order water absorption. Because there was little $\mathrm{H}_{2} \mathrm{SO}_{4}$ acid fog produced in the experiment, the absorption solution containing $\mathrm{NaOH}$ was used.

\subsection{Precision of the method}

Under the above optimum conditions, for $0.3-$ $0.5 \mathrm{~g}$ mulberry leaves, the precision of the method was determined and the results are shown in Table 2. The RSD was $3.7 \%$.

\subsection{Recovery}

The recovery of the method was determined with mulberry leaf samples and the results are shown in Table 3. The recovery was $95.9-104.4 \%$.

\subsection{Determination of fluorine in tea leaf}

Two kinds of tea leaves produced from two location were processed by the separation method developed. The fluorides separated were determined by spectrophotometry. One sample was of older leaves and tender leaves of Fuding Tea produced on the purple soil of Zheyin Mountain. The other sample was tea from Mingshan 23 produced on the yellow soil of Mingshan county. The tea leaves sample was a gift from Professor Yao in the Department of Chemistry in Sichuan Normal University. The results are shown in Table 4.

The ratio of fluorine in older and tender leaves of Fuding was 3.4:1, and that of Mingshan 4.2:1. The difference in fluorine between the older and tender leaves among the different soils, locations and types was large. Furthermore, fluorine was higher in the older leaves than in the tender because of enrichment of the leaves from the fluorine in the air.

Tea is a popular drink in China. The above results suggest that tea made from the tender leaves should be taken in areas containing high fluorine, and should be drunk less, to prevent chronic poisoning owing to the surplus fluorine absorbed. In areas of low fluorine, tea made of the older leaves, which contain more fluorine, should be taken, thus removing the need to add fluorine to the water to prevent disease from lack of fluorine.

\section{Conclusions}

A simple and rapid method to separate the fluoride from plant samples has been established. It combines wet digestion $\left(\mathrm{H}_{2} \mathrm{SO}_{4}\right.$ and $\mathrm{H}_{2} \mathrm{O}_{2}$ were used) with distillation using air as the carrier gas. The volume of collected liquid is several millilitres. The procedure to handle a sample takes only 25-30 min. The proposed method is simpler and more rapid than distillation after mineralization in an alkaline medium. Diffusion allows separation of a large number of samples at the same time. However, the proposed method is more 
rapid than diffusion when only a few samples need to be handled. That is, diffusion is adopted when a lot of samples need to be handled and the proposed method is adopted when only a few samples need to be handled.

\section{Acknowledgements}

The support of the National Natural Science Foundation of China is greatly appreciated.

\section{References}

[1] H.H. Willard, O.B. Winter, Ind. Eng. Chem. Anal. Ed. 5 (1933) 7.

[2] J.K. Wilkeysn, Anal. Chem. 47 (1975) 2053.

[3] M. Nedeljkovic, B. Antonijevic, V. Matovic, Analyst (London) 116 (1991) 477.

[4] B. Culik, Anal. Chim. Acta 189 (1986) 329.

[5] Scientific Research Cooperation Group of Analytical Methods for Environmental Pollution, Analytical Methods for Environmental Pollution, vol. 1, 2nd ed., Inorganic Analysis, Science Press, Beijing, 1987, pp. 331-337 (in Chinese). 